\section{Assessing Microalgal Morphology from Century-Old Herbarium Sheets using SEM}

Linton, E. W. ${ }^{1}$, Farmer, M. A. ${ }^{2}$, \& Triemer, R. E. ${ }^{1}$

1) Department of Plant Biology, Michigan State University, East Lansing, MI 48824 USA

2) Center for Advanced Ultrastructural Research, 105 Barrow Hall, The University of Georgia, Athens, GA 30602 USA lintoe@msu.edu

Traditionally, type specimens have not been deposited for most unicellular algae. There are few known holotypes and those that are available are often of limited use. Samples from taxa described before 1900 commonly consist of materials dried down on herbarium sheets or mica. Dried algal samples can be rehydrated, but preservation is very poor and little structure can be determined from them. Whether wet or dry, the amount of information that can be derived from such samples using conventional light microscopy is limited. However, we were able to derive high-resolution images from Euglena spirogyra cells that were dried on mica chips in October of 1899, stored in the Michigan State University herbarium and viewed on a FESEM. The overall shape of the cell body and the arrangement and ornamentation of the pellicle strips were clearly visible. Because of this success we decided to examine a variety of algal samples that had been preserved on mica. Algae such as Staurastrum, Scenedesmus, or Mallomonas (particularly the scales), retained the most structure while others such as Pediastrum and Pandorina, retained sufficient structure to allow their identification. We suggest that FESEM should be more broadly used for assessing structure in dried herbarium samples.

\section{Materials and Methods}

All samples were air-dried onto mica chips 75 - 105 years ago. Approximately a $3 \mathrm{~mm}$ X $5 \mathrm{~mm}$ sample from each mica chip was removed using a razor blade, and placed onto a SEM stub using double-sided carbon tape. Samples were gold coated and viewed on a JEOL 6300F FieldEmission SEM at $10-\mathrm{kV}$. Images were captured digitally and stored on $\mathrm{CD}-\mathrm{R}$ media. Final image processing

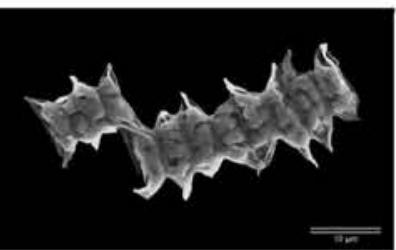

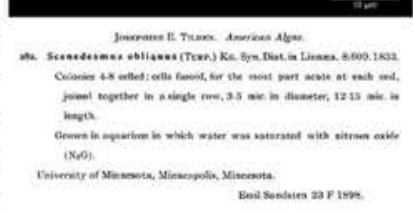
was done in PhotoShop 7 on a Macintosh computer.

\section{Conclusions}

These results show that algae (other than diatoms) deposited in herbariums, even those deposited 100 years or more ago, can be positively identified using FESEM. This study demonstrates the potential of using dehydrated herbarium samples for resolving taxonomic issues when the original description and/or illustration(s) are inadequate, questionable or when the taxon is in need of revision.

Therefore, we recommend the use of FESEM for use with microalgal herbarium specimens with two caveats. First, samples with hard, shell-like surfaces, scales or with distinctive morphologies are more easily and reliable identified. Second, while samples stored on mica chips are reliable those on herbarium paper tend to dehydrate more, retained less structure and flatten into the fibers of the herbarium paper. Thus, these samples are not useful for identification.
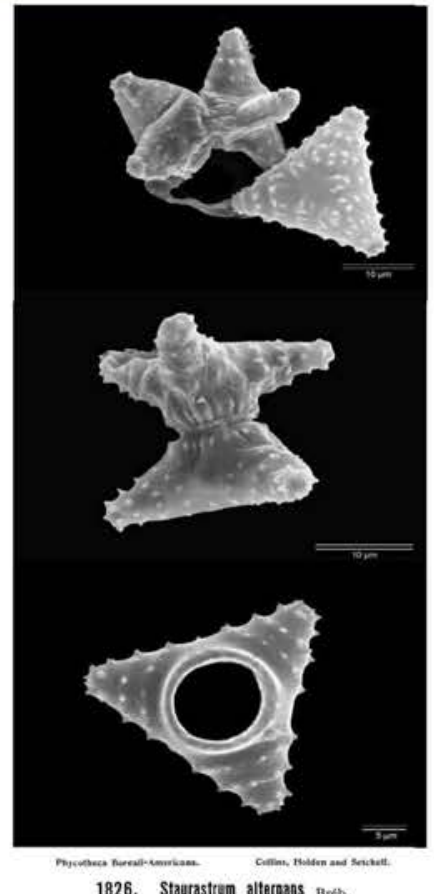

1826. Staurastrom alternans Brebo.

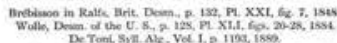

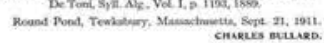
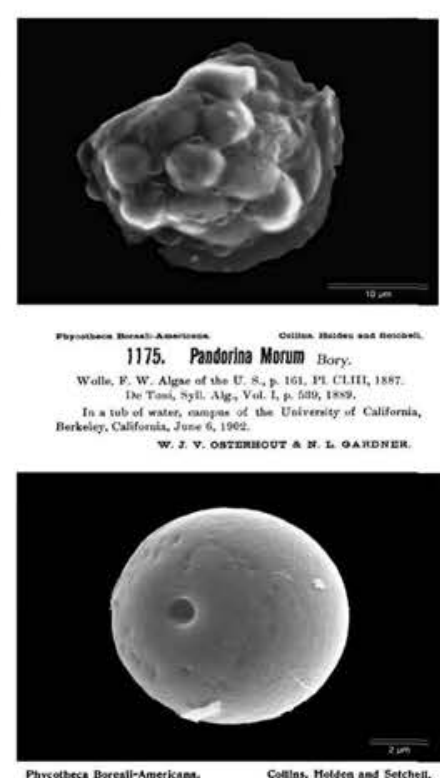

Trachelomonas volvocina EHRB. Among Mougeotia in a poot in a pasture, Exeter, Rhode
and, April 30,1911 .

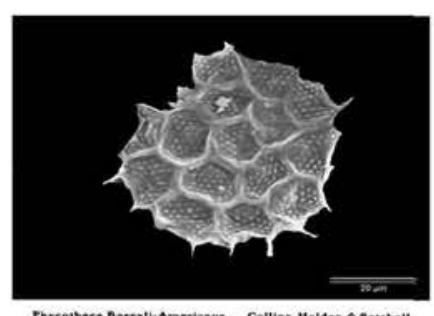

1729. Pedlastrum Beryanum (Turp) Meneg.

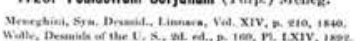

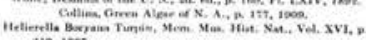
inc......til MARLKs gutian

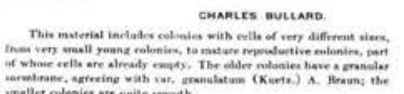

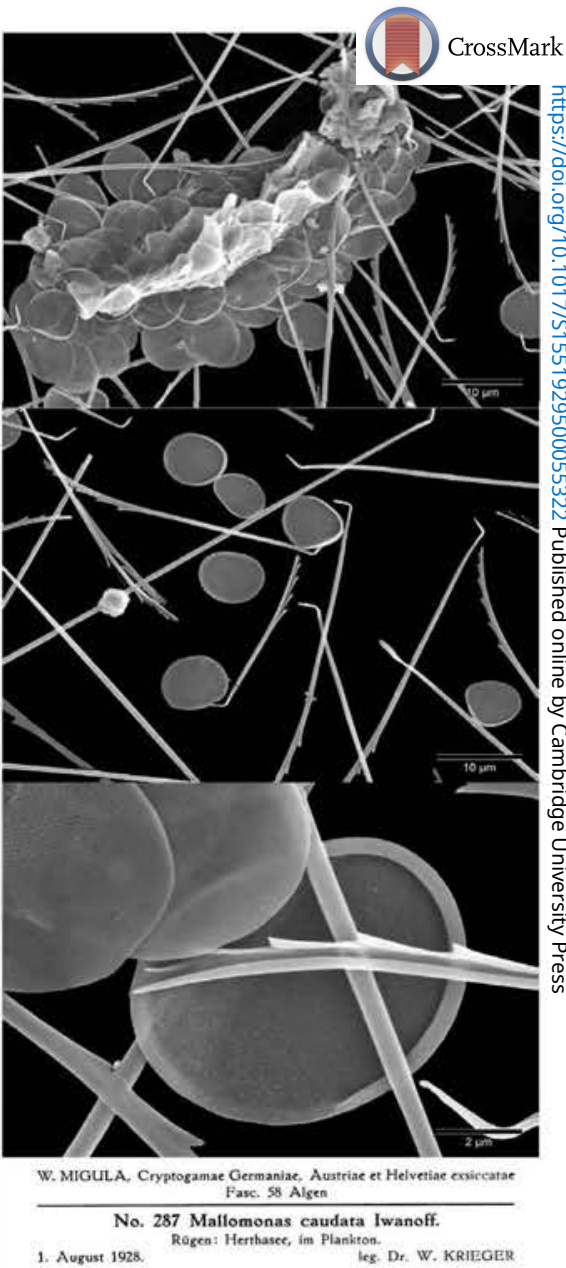
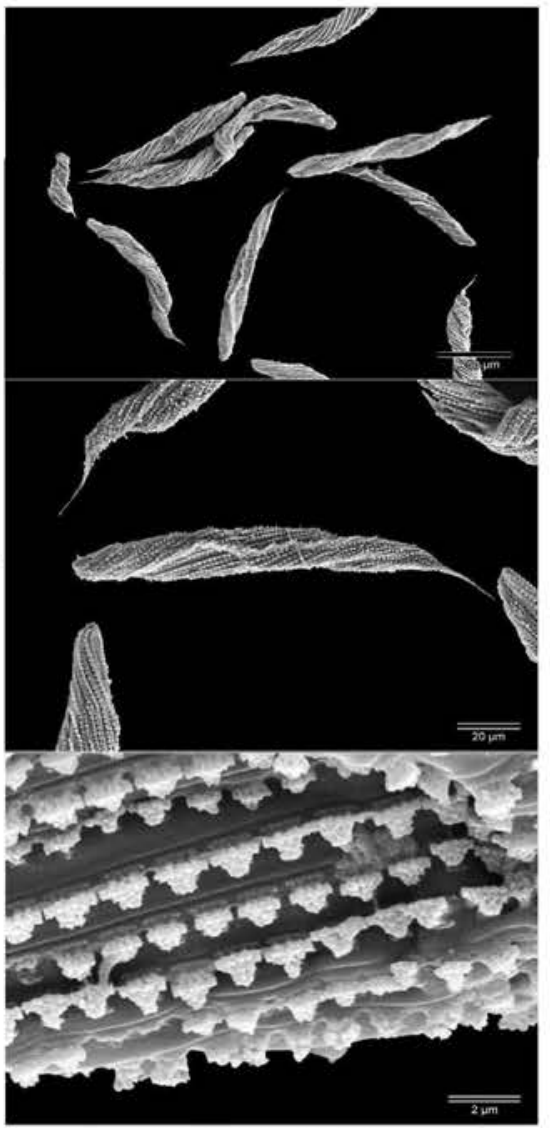

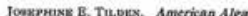

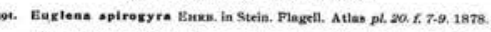
Plant (or animal) elongate, sometimes sigmoid, unidiliate, 195 mie. in length; longitudinal strim finely keobbed; paramylon-bodics large, two in number 


\section{See More. Guess Less.}
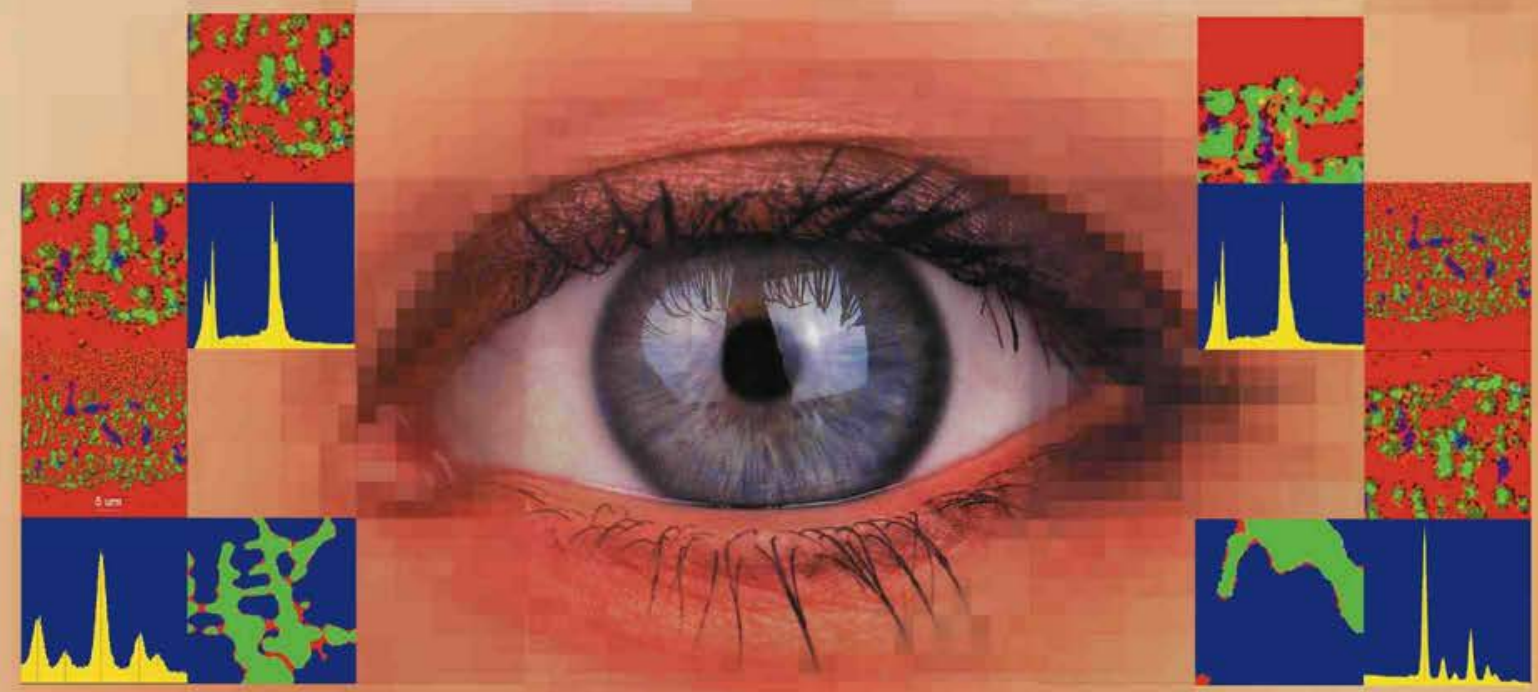

\section{NORAN System SIX for $\mathrm{x}$-ray microanalysis}

You no longer need to optimize your $x$-ray microanalysis parameters for just a few elements. That's because Thermo's NORAN System SIX x-ray microanalysis system gives you a complete data set with every run.

Built around our spectral imaging technology, NORAN System SIX:

- Eliminates guesswork by automatically optimizing data collection

- Gives you a full spectrum for every pixel of your electron microscope image

- Allows analysis and re-analysis of the full data set any time, anywhere.

Open your eyes to the world of NORAN System SIX at www.thermo.com/microanalysis or contact us for more information.

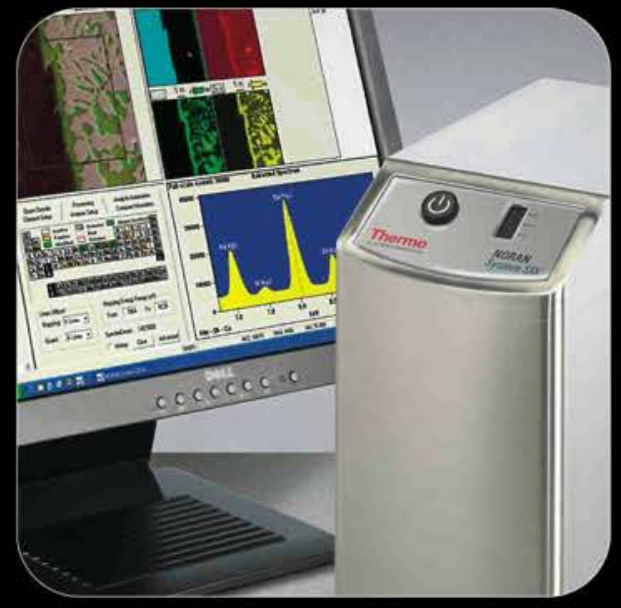

Telephone: 1-800-532-4752 • Email: analyze@thermo.com

Look closer for answers 